\title{
Efeito de acibenzolar-S-metil, mananoligossacarídeo bioflavonóides cítricos no controle da mancha-aquosa e no crescimento do meloeiro
}

\author{
Clêidio da Paz Cabral ${ }^{1}$, Marco Aurélio Siqueira da Gama ${ }^{1}$, Elizabethe Rodrigues Alexandre ${ }^{1}$, Rosa de \\ Lima Ramos Mariano ${ }^{1}$ \& Elineide Barbosa da Silveira ${ }^{2}$
}

${ }^{1}$ Departamento de Agronomia/Fitossanidade; ${ }^{2}$ Departamento de Biologia/Microbiologia, Universidade Federal Rural de Pernambuco UFRPE, 52171-030, Recife, PE, Brasil

Autor para correspondência: Elineide B. Silveira, e-mail: elineidebs@yahoo.com.br

\begin{abstract}
RESUMO
Foi estudado o efeito de acibenzolar-S-metil (ASM), mananoligossacarídeos (MOS) e bioflavonóides cítricos (BFC) no controle da mancha-aquosa causada por Acidovorax citrulli em meloeiros tipo Amarelo (híbrido AF4945) e tipo Pele de Sapo (híbrido Nilo), em diferentes épocas de aplicação (10 e 15 dias após a emergência das plântulas) e dosagens (ASM 25; 50 e 75 mg i.a. $\mathrm{L}^{-1}$; MOS 0,$5 ; 1,0$ e 1,5 p.c. $\mathrm{L}^{-1}$; BFC 2; 3 e $4 \mathrm{~mL}$ p.c. $\mathrm{L}^{-1}$ ); e também no crescimento da planta em solo com ou sem suplementação de NPK. A melhor época para aplicação dos indutores foi dez dias após a emergência das plântulas. Considerando os dois genótipos, ASM $\left(50 \mathrm{mg}\right.$ i.a. $\left.\mathrm{L}^{-1}\right)$ e BFC ( $3 \mathrm{~mL}$ p.c. $\mathrm{L}^{-1}$ ) elevaram o período de incubação em até 13 e 8 dias e reduziram a incidência da mancha-aquosa em 88 e $60 \%$; o índice de doença em 96 e 88\%; e a área abaixo da curva de progresso da doença em 94 e $74 \%$, respectivamente. No entanto, independente do nível de NPK no solo, ASM e BFC reduziram a altura, biomassa fresca e seca da parte aérea das plantas de meloeiro em até 24; 41 e 34\%, respectivamente.
\end{abstract}

Palavras-chave: Acidovorax citrulli, Cucumis melo, indutores de resistência, custo fisiológico.

\begin{abstract}
Effect of acibenzolar-S-methyl, mannano-oligosaccharides and citrus bioflavonoids on the control of bacterial fruit blotch and growth of melon plant

The effect of acibenzolar-S-methyl (ASM), mannano-oligosaccharides (MOS) and citrus bioflavonoids (BFC) was studied for control of bacterial fruit blotch of yellow melon (hybrid AF4945) and Pele de Sapo melon (hybrid Nilo), evaluating different application periods (10 and 15 days after plant emergence), and dosages (acibenzolar-S-methyl 25; 50 and $75 \mathrm{mg}^{2}$.i. L $\mathrm{L}^{-1}$; mannano-oligosaccharides 0.5; 1.0 and 1.5 c.p. $\mathrm{L}^{-1}$; citrus bioflavonoids $2 ; 3$ and $4 \mathrm{~mL}$ c.p. $\left.\mathrm{L}^{-1}\right)$ and also on plant growth in soil supplemented or not with NPK. The best period for application was 10 days after plant emergence. Considering both genotypes, ASM (50 mg a.i. $\left.\mathrm{L}^{-1}\right)$ and BFC $\left(3 \mathrm{~mL}\right.$ c.p. $\left.\mathrm{L}^{-1}\right)$ increased incubation period until 13 and 8 days and reduced disease incidence by 88 and 60\%; disease index by 96 and $88 \%$; and area under disease progress curve by 94 and 74\%, respectively. However, independent of NPK level in the soil ASM and BFC reduced melon plant height by $24 \%$; they also reduced fresh and dry shoot biomass by $41 \%$ and $34 \%$, respectively.
\end{abstract}

Keywords: Acidovorax citrulli, Cucumis melo, resistance inducers, physiological cost.

A mancha-aquosa causada pela bactéria Acidovorax citrulli (Schaad et al.) Schaad et al. é uma importante doença para a cultura do meloeiro (Cucumis melo L.), ocasionando depreciação do valor comercial do fruto e grandes perdas na produção, que podem chegar a até $100 \%$ em períodos chuvosos (Mariano \& Silveira, 2002). A inexistência de medidas efetivas de controle dessa doença no Brasil torna imprescindível a realização de pesquisas que visem à obtenção de métodos alternativos de controle. No contexto da proteção de plantas, a resistência induzida

Parte da Dissertação de Mestrado do primeiro autor. Universidade Federal Rural de Pernambuco. Recife PE. 2009. pode ser considerada como uma medida de controle alternativo. Ela envolve a ativação de genes de defesas inativos existentes nas plantas em resposta ao tratamento com agentes indutores. Entre os indutores utilizados no controle de doenças de plantas encontram-se acibenzolarS-metil, mananoligossacarídeos e bioflavonóides cítricos (Sticher et al., 1997; Guzzo, 2004; Cavalcanti et al., 2006). No entanto, a utilização de indutores nem sempre resulta em benefícios na produção, visto que a ativação de resistência demanda custo de energia por parte da planta sob condições em que não seria necessário, como na ausência do patógeno (Dietrich et al., 2005).

No Brasil, Nascimento et al. (2003) e Sales Júnior et al. (2007) relataram a eficiência do acibenzolar-S-metil (1g 
$20 \mathrm{~L}^{-1}$ de água) em campo, no controle da mancha-aquosa e aumento da produtividade de meloeiro tipo Pele de Sapo (cv. Sancho) e tipo Amarelo (cv. Gold Mine), embora sem testar também o efeito no crescimento da planta. O objetivo deste trabalho foi estudar o efeito de indutores de resistência no controle da mancha-aquosa, em diferentes épocas de aplicação e dosagens; e no crescimento do meloeiro.

Em todos os experimentos, sementes de melão tipo Amarelo (híbrido AF4945) e tipo Pele de Sapo (híbrido Nilo) foram semeadas em vasos plásticos com capacidade de 2,8 L, contendo solo esterilizado com brometo de metila e substrato Tropstrato ${ }^{\circledR}(3: 1 \mathrm{v}: \mathrm{v})$ mantendo-se uma planta por vaso. No primeiro experimento, os indutores acibenzolarS-metil (ASM) (Bion ${ }^{\circledR}$, Syngenta), mananoligossacarídeo (MOS) fosforilado derivado da parede celular da levedura Saccharomyces cerevisae 1026 (Agro-Mos ${ }^{\circledR}$, Improcrop ${ }^{\circledR}$ ) e uma mistura principalmente de bioflavanóides cítricos (BFC) (Ecolife ${ }^{\circledR}$, Quinabra) foram pulverizados, até o ponto de escorrimento, nas dosagens de $25 \mathrm{mg}$ i.a. $\mathrm{L}^{-1}, 1$ $\mathrm{mL}$ p.c. $\mathrm{L}^{-1}$ e $2 \mathrm{~mL}$ p.c. $\mathrm{L}^{-1}$, respectivamente, aos 10 e 15 dias após a emergência das plântulas. A inoculação de $A$. citrulli, isolado Ac1 pertencente à Coleção de Culturas do Laboratório de Fitobacteriologia da UFRPE, foi realizada aos 20 dias após a emergência das plântulas (10 ou 5 dias após aplicação dos indutores), também por meio de pulverização, com suspensão na concentração de $3,4 \times 10^{7}$ UFC $\mathrm{mL}^{-1}$. Antes e após a inoculação, as plantas foram submetidas à câmara úmida por 48 horas. $\mathrm{O}$ delineamento experimental para cada genótipo de meloeiro e indutor foi inteiramente casualizado, com cinco repetições, sendo a unidade experimental constituída por cinco folhas da planta.

Após a seleção da melhor época de aplicação, foram testadas diferentes dosagens dos indutores: ASM 25, 50 e $75 \mathrm{mg}$ i.a. $\mathrm{L}^{-1}$; MOS- $0,5,1$ e $1,5 \mathrm{~mL}$ p.c. $\mathrm{L}^{-1}$; e BFC- 2, 3 e $4 \mathrm{~mL}$ p.c. $\mathrm{L}^{-1}$. O delineamento experimental foi inteiramente casualizado, com cinco repetições, sendo a unidade experimental constituída por duas folhas da planta. Nos dois experimentos a incidência da doença foi avaliada diariamente e a severidade a intervalos de quatro dias, contados a partir da inoculação até 20 dias após, estimada com o auxílio de escala descritiva (Araújo et al., 2005). Foram determinados: a) período de incubação (PI); b) incidência (INC) da mancha-aquosa; c) índice de doença (IDO), aos 40 dias após a emergência, calculado de acordo com Mckinney (1923); e d) a área abaixo da curva de progresso da doença (AACPD), calculada de acordo com Shaner \& Finney (1977).

No terceiro experimento, as sementes foram plantadas em vasos contendo solos com e sem suplementação de NPK. No solo natural apresentando: $\mathrm{pH}-5,4 ; \mathrm{P}-11\left(\mathrm{mg}\left(\mathrm{dm}^{3}\right)^{-1}\right)$; $\mathrm{Na}^{+}-0,03\left(\mathrm{cmol}_{\mathrm{c}}\left(\mathrm{dm}^{3}\right)^{-1}\right) ; \mathrm{K}^{+}-0,06\left(\mathrm{cmol}_{\mathrm{c}}\left(\mathrm{dm}^{3}\right)^{-1}\right) ; \mathrm{Ca}^{+2}$ $+\mathrm{Mg}^{+2}-1,20\left(\mathrm{cmol}_{\mathrm{c}}\left(\mathrm{dm}^{3}\right)^{-1}\right) ; \mathrm{Ca}^{+2}-0,75\left(\mathrm{cmol}_{\mathrm{c}}\left(\mathrm{dm}^{3}\right)^{-1}\right)$; $\mathrm{Al}^{+3}-0,25\left(\mathrm{cmol}_{\mathrm{c}}\left(\mathrm{dm}^{3}\right)^{-1}\right) ; \mathrm{H}+\mathrm{AL}-5,5\left(\mathrm{cmol}_{\mathrm{c}}\left(\mathrm{dm}^{3}\right)^{-1}\right) ; \mathrm{N}$ - 0,05 dag kg-1 ; C.O. - 12,97 $\mathrm{g} \mathrm{kg}^{-1}$; M.O. - 12,97 $\mathrm{g} \mathrm{kg}^{-1}$, foi realizada suplementação mineral com os macronutrientes $\mathrm{N}$ (sulfato de amônio) - $200\left(\mathrm{mg}\left(\mathrm{dm}^{3}\right)^{-1}\right), \mathrm{P}_{2} \mathrm{O}_{5}$ (superfosfato triplo) - $250\left(\mathrm{mg}\left(\mathrm{dm}^{3}\right)^{-1}\right)$, e $\mathrm{K}_{2} \mathrm{O}$ (cloreto de potássio) - 150 $\left(\mathrm{mg}\left(\mathrm{dm}^{3}\right)^{-1}\right)$, de acordo com Nascimento et al. (2006) e conforme as exigências nutricionais do meloeiro. ASM e BFC foram avaliados nas dosagens $50 \mathrm{mg}$ i.a. $\mathrm{L}^{-1}$ e $3 \mathrm{~mL}$ p.c. $\mathrm{L}^{-1}$, respectivamente. $\mathrm{O}$ delineamento experimental foi inteiramente casualizado em arranjo fatorial $2 \times 3$ (dois tipos de solo e dois indutores mais testemunha pulverizada com água), com cinco repetições, sendo a unidade experimental constituída por uma planta. Aos 45 dias após a emergência, as plantas foram avaliadas quanto à altura (AP) e biomassa fresca (BFPA) e seca (BSPA) da parte aérea. A AP foi medida da superfície do solo até o ponto mais alto da planta, a BFPA foi quantificada após a retirada das plantas dos vasos, separando o sistema radicular da parte aérea na região de transição entre a raiz e o colo da planta, e a BSPA foi determinada após as plantas serem colocadas em sacos de papel e submetidas à secagem em estufa a $37^{\circ} \mathrm{C}$, até peso constante. Todos os experimentos foram realizados duas vezes e como apresentaram resultados similares, foram analisados como repetição no tempo. Os dados obtidos para cada genótipo foram submetidos separadamente a análise de variância, com auxílio do programa $\mathrm{SAEG}^{\circledR}$ - Sistema para análises estatísticas e genéticas, Viçosa, UFV, versão 9.0, 2005.

A aplicação de ASM e BFC em meloeiro Amarelo aos dez dias após a emergência das plântulas proporcionou diferenças significativas $(\mathrm{P} \leq 0,05)$ em relação à aplicação aos 15 dias, em todas as variáveis analisadas (PI, INC, IDO e AACPD). Diferenças significativas em meloeiro Pele de Sapo foram apenas observadas no PI e IDO quando o BFC foi aplicado aos dez dias (Tabela 1). Com relação a MOS não foram verificadas diferenças entre os dois períodos de aplicação. A aplicação dos indutores 10 dias antes da inoculação do patógeno foi selecionada para utilização nos testes posteriores. Nascimento et al. (2003), testando a aplicação de ASM em meloeiro Pele de Sapo a intervalos de 7 e 14 dias, a partir dos 15 dias do plantio, num total de 8 e 4 aplicações respectivamente, obtiveram controle da mancha-aquosa com redução de perdas superior a $10 \mathrm{tha}^{-1}$, independente da época e número de aplicações.

Os indutores nas diversas dosagens diferiram significativamente $(\mathrm{P} \leq 0,05)$ da testemunha em relação ao PI, INC, IDO e AACPD, com exceção do BFC nas dosagens 2 e $4 \mathrm{~mL}$ p.c. $\mathrm{L}^{-1}$ em relação a INC no meloeiro Pele de Sapo (Tabela 2). Mesmo apresentando bons resultados no controle da mancha-aquosa, o produto MOS causou fitotoxidez às plantas de meloeiro em todas as dosagens testadas. Em meloeiro Amarelo, respectivamente para ASM $50 \mathrm{mg}$ i.a. $\mathrm{L}^{-1}$ e BFC3 mL p.c. $\mathrm{L}^{-1}$, foram verificados aumentos do PI de 12 e 7 dias e reduções de INC de 78 e 35\%; IDO de 93 e $78 \%$; e AACPD de 88 e 69\%. No meloeiro Pele de Sapo os valores obtidos foram: PI de 13 e 8 dias, INC de 88 e $60 \%$, IDO de 96 e $88 \%$ e AACPD de 94 e 74\%. Ambos indutores nestas dosagens foram selecionados por apresentarem maior eficiência no controle da mancha-aquosa nos dois genótipos. 
Efeito de acibenzolar-S-metil, mananoligossacarídeo e bioflavonóides cítricos...

TABELA 1 - Efeito da época de aplicação dos indutores acibenzolar-S-metil, mananoligossacarídeo e bioflavonóides cítricos no controle da mancha-aquosa em meloeiro tipo Amarelo (hibrido AF4945) e tipo Pele de Sapo (híbrido Nilo), avaliado por componentes epidemiológicos, em casa de vegetação

\begin{tabular}{|c|c|c|c|c|c|c|c|c|c|c|c|c|}
\hline \multirow{2}{*}{$\begin{array}{l}\text { Período } \\
\text { de } \\
\text { aplicação } \\
\text { (dias) }^{1}\end{array}$} & \multicolumn{4}{|c|}{$\begin{array}{c}\text { Acibenzolar-S-Metil } \\
25 \text { mg.i.a. } \mathbf{L}^{-1}\end{array}$} & \multicolumn{4}{|c|}{$\begin{array}{c}\text { Mananoligossacarídeo } \\
\text { 0,5mL.p.c. } \mathrm{L}^{-1}\end{array}$} & \multicolumn{4}{|c|}{$\begin{array}{c}\text { Bioflavonóides cítricos } \\
2 \mathrm{mLp.c.} \mathrm{L}^{-1}\end{array}$} \\
\hline & $\begin{array}{c}\mathrm{PI}^{2} \\
\text { (dias) }\end{array}$ & $\begin{array}{l}\text { INC } \\
(\%)\end{array}$ & IDO & AACPD & $\begin{array}{c}\text { PI } \\
\text { (dias) }\end{array}$ & $\begin{array}{l}\text { INC } \\
(\%)\end{array}$ & IDO & AACPD & $\begin{array}{c}\text { PI } \\
\text { (dias) }\end{array}$ & $\begin{array}{l}\text { INC } \\
(\%)\end{array}$ & IDO & AACPD \\
\hline \multicolumn{13}{|c|}{ Meloeiro tipo Amarelo } \\
\hline 10 & $15,8 \mathrm{a}$ & $10,0 \mathrm{a}$ & $1,6 \mathrm{a}$ & $0,4 \mathrm{a}$ & $5,7 \mathrm{a}$ & $67,0 \mathrm{a}$ & $4,4^{\mathrm{a}}$ & $3,1 \mathrm{a}$ & $7,8 \mathrm{a}$ & $59,0 \mathrm{a}$ & $3,6 \mathrm{a}$ & $2,5 \mathrm{a}$ \\
\hline 15 & $11,2 \mathrm{~b}$ & $40,0 \mathrm{~b}$ & $2,8 b$ & $1,7 \mathrm{~b}$ & $5,2 \mathrm{a}$ & $67,0 \mathrm{a}$ & $4,4^{\mathrm{a}}$ & $3,2 \mathrm{a}$ & $3,7 b$ & $76,0 \mathrm{~b}$ & $5,8 \mathrm{~b}$ & $4,2 b$ \\
\hline \multicolumn{13}{|c|}{ Meloeiro tipo Pele de Sapo } \\
\hline 10 & $13,9 \mathrm{a}$ & $27,0 \mathrm{a}$ & $1,8 \mathrm{a}$ & $1,1 \mathrm{a}$ & $9,6 \mathrm{a}$ & $51,0 \mathrm{a}$ & $4,0 \mathrm{a}$ & $2,4 a$ & $7,6 a$ & $59,0 \mathrm{a}$ & $3,4 \mathrm{a}$ & $2,7 \mathrm{a}$ \\
\hline 15 & $12,5 \mathrm{a}$ & $37,0 \mathrm{a}$ & $2,8 \mathrm{a}$ & $1,6 \mathrm{a}$ & $7,6 \mathrm{a}$ & $56,0 \mathrm{a}$ & $4,6^{\mathrm{a}}$ & $2,9 \mathrm{a}$ & $4,4 \mathrm{~b}$ & $73,0 \mathrm{~b}$ & $4,8 b$ & $3,6 \mathrm{a}$ \\
\hline
\end{tabular}

${ }^{1}$ Meloeiros pulverizados com indutores aos 10 e 15 dias após a emergência das plântulas e inoculados com Acidovorax citrulli 20 dias após a emergência das plântulas;

${ }^{2} \mathrm{PI}$ = período de incubação, obtido pelo número de dias entre a inoculação e o surgimento dos sintomas da doença; INC = incidência da doença -determinada pela porcentagem de plantas infectadas em relação ao total de plantas inoculadas; IDO = índice de doença, aos 40 dias após a emergência, calculado de acordo com Mckinney (1923); AACPD = área abaixo da curva de progresso da doença, calculada de acordo com Shaner \& Finney (1977);

${ }^{3}$ Média de 10 repetições. Médias seguidas da mesma letra na coluna para cada genótipo de meloeiro não diferem significativamente entre si pelo teste $\mathrm{T}(\mathrm{P} \leq 0,05)$.

TABELA 2 - Efeito de diferentes dosagens de acibenzolar-S-metil (ASM), mananoligossacarídeo (MOS) e bioflavonóides cítricos (BFC) no controle da mancha-aquosa em meloeiro tipo Amarelo (hibrido AF4945) e tipo Pele de Sapo (híbrido Nilo), avaliado por componentes epidemiológicos, em casa de vegetação

\begin{tabular}{|c|c|c|c|c|c|c|c|c|}
\hline \multirow[t]{2}{*}{ Tratamento $^{1}$} & \multicolumn{2}{|c|}{$\begin{array}{l}\text { Período de } \\
\text { incubação }^{2} \\
\text { PI (dias) }\end{array}$} & \multicolumn{2}{|c|}{$\begin{array}{c}\text { Incidência da doença } \\
\text { INC }(\%)\end{array}$} & \multicolumn{2}{|c|}{$\begin{array}{c}\text { Índice de doença } \\
\text { IDO }\end{array}$} & \multicolumn{2}{|c|}{$\begin{array}{c}\text { Área abaixo da curva } \\
\text { de progresso da doença } \\
\text { AACPD }\end{array}$} \\
\hline & Amarelo & $\begin{array}{c}\text { Pele de } \\
\text { Sapo }\end{array}$ & Amarelo & $\begin{array}{l}\text { Pele de } \\
\text { Sapo }\end{array}$ & Amarelo & $\begin{array}{l}\text { Pele de } \\
\text { Sapo }\end{array}$ & Amarelo & $\begin{array}{l}\text { Pele de } \\
\text { Sapo }\end{array}$ \\
\hline Testemunha & $3,8 \mathrm{~d}^{3}$ & $3,8 \mathrm{e}$ & $100,0 \mathrm{a}$ & $100,0 \mathrm{a}$ & $11,7 \mathrm{a}$ & $11,7 \mathrm{a}$ & $5,7 \mathrm{a}$ & $5,7 \mathrm{a}$ \\
\hline ASM $25 \mathrm{mg}$ i.a. $\mathrm{L}^{-1}$ & $12,4 \mathrm{ab}$ & $13,2 \mathrm{ab}$ & $35,0 \mathrm{de}$ & $37,5 \mathrm{~d}$ & $1,5 \mathrm{de}$ & $1,5 \mathrm{ef}$ & $1,4 \mathrm{de}$ & $1,0 \mathrm{fg}$ \\
\hline ASM50 mg i.a. $\mathrm{L}^{-1}$ & $15,8 \mathrm{a}$ & $16,4 \mathrm{a}$ & $22,5 \mathrm{e}$ & $12,5 \mathrm{e}$ & $0,8 \mathrm{e}$ & $0,5 \mathrm{f}$ & $0,7 \mathrm{e}$ & $0,4 \mathrm{~g}$ \\
\hline ASM75 mg i.a. $\mathrm{L}^{-1}$ & $12,8 \mathrm{ab}$ & $12,6 \mathrm{bc}$ & $40,0 \mathrm{~cd}$ & $40,0 \mathrm{~d}$ & 2,2 cde & $2,1 \mathrm{de}$ & $1,5 \mathrm{de}$ & $1,3 \mathrm{ef}$ \\
\hline $\operatorname{MOS} 0,5 \mathrm{~mL}$ p.c. $\mathrm{L}^{-1}$ & $9,0 \mathrm{bc}$ & $12,0 \mathrm{bc}$ & $67,5 \mathrm{~b}$ & $47,5 \mathrm{~cd}$ & $4,2 \mathrm{bc}$ & 2,6 cde & $3,1 \mathrm{~b}$ & 1,7 cdef \\
\hline MOS $1 \mathrm{~mL}$ p.c. $\mathrm{L}^{-1}$ & $10,5 \mathrm{bc}$ & $9,9 \mathrm{c}$ & $50,0 \mathrm{bcd}$ & $65,0 \mathrm{bc}$ & $2,9 \mathrm{bcd}$ & $3,2 \mathrm{~cd}$ & $2,9 \mathrm{bc}$ & 2,2 cde \\
\hline $\operatorname{MOS} 1,5 \mathrm{~mL}$ p.c. $\mathrm{L}^{-1}$ & $9,8 \mathrm{bc}$ & $9,7 \mathrm{c}$ & $57,5 \mathrm{bc}$ & $57,5 \mathrm{~cd}$ & $3,6 \mathrm{bc}$ & $3,8 \mathrm{~cd}$ & $2,3 \mathrm{bcd}$ & $2,4 \mathrm{bcd}$ \\
\hline BFC 2 mL p.c. $\mathrm{L}^{-1}$ & $8,4 \mathrm{c}$ & $6,6 \mathrm{~d}$ & $70,0 \mathrm{~b}$ & $87,5 \mathrm{ab}$ & $4,9 \mathrm{~b}$ & $4,2 \mathrm{bc}$ & $3,0 \mathrm{bc}$ & $2,8 \mathrm{bc}$ \\
\hline BFC $3 \mathrm{~mL}$ p.c. $\mathrm{L}^{-1}$ & $10,5 \mathrm{bc}$ & $11,9 \mathrm{bc}$ & $65,0 \mathrm{~b}$ & $40,0 \mathrm{~d}$ & $2,6 \mathrm{bcd}$ & $1,4 \mathrm{ef}$ & $1,8 \mathrm{~cd}$ & 1,4 def \\
\hline BFC 4 mL p.c. $\mathrm{L}^{-1}$ & $8,0 \mathrm{c}$ & $6,8 \mathrm{~d}$ & $72,5 \mathrm{~b}$ & $85,0 \mathrm{ab}$ & $4,5 \mathrm{~b}$ & $6,0 \mathrm{~b}$ & $2,7 \mathrm{bc}$ & $3,5 \mathrm{~b}$ \\
\hline $\mathrm{CV} \%$ & 18,1 & 15,3 & 24,4 & 25,6 & 24,5 & 22,1 & 17,6 & 17,3 \\
\hline
\end{tabular}

${ }^{1}$ Meloeiros tratados com os indutores e inoculados com Acidovorax citrulli aos 10 e 20 dias após emergência das plântulas, respectivamente; ${ }^{2} \mathrm{PI}$ - obtido pelo número de dias entre a inoculação e o surgimento dos sintomas da doença; INC - determinada pela porcentagem de plantas infectadas em relação ao total de plantas inoculadas; IDO - aos 40 dias após a emergência, calculado de acordo com Mckinney (1923); AACPDcalculada de acordo com Shaner \& Finney (1977);

${ }^{3}$ Média de 10 repetições. Dados transformados segundo $\sqrt{ } \mathrm{x}+1$. Médias seguidas da mesma letra na coluna não diferem significativamente entre si pelo teste de Duncan $(\mathrm{P} \leq 0,05)$.

Existem poucos trabalhos com ASM no patossistema meloeiro - A. citrulli, mas a eficiência desse produto também tem sido verificada em meloeiro com outras interações e em outros patossistemas. No entanto, não existem muitos estudos testando BFC contra doenças bacterianas e nenhum foi encontrado com o patossistema em questão. Em trabalho de campo, Sales Júnior et al. (2007) verificaram redução da incidência da mancha-aquosa em meloeiro Amarelo (cv. Gold Mine) quando se utilizou ASM nas concentrações de $25 \mathrm{~g} \mathrm{ha}^{-1}$ e $50 \mathrm{~g} \mathrm{ha}^{-1}$. Em meloeiro Pele de Sapo (cv. Sancho), também foi obtido controle da mancha-aquosa por Silva et al. (2002) e Nascimento et al. (2003). Aplicações 
de ASM em pré-colheita em melões também induziram resistência sistêmica na folhagem e diminuíram o inóculo dos patógenos Alternaria, Fusarium e Trichothecium, sendo mais eficientes no controle da podridão-defusário (Huang et al., 2000). Sales Júnior et al. (2005) observaram que os menores índices de infecção de oídio em meloeiro Pele de Sapo (cv. Sancho) foram obtidos nas plantas tratadas com ASM nas dosagens de 1 e 2 g $20 \mathrm{~L}^{-}$ ${ }^{1}$ de água quando comparados aos tratamentos com BFC e MOS, independente da época de aplicação. A utilização preventiva de ASM reduziu em cerca de $50 \%$ a severidade da queima bacteriana (Xanthomonas axonopodis pv. allii) em alho (Lang et al., 2007) e significativamente a infecção por Xanthomonas oryzae pv. oryzae em arroz (Mohan Babu et al., 2005). Já BFC pulverizado em plantas de tomate conferiu $39 \%$ de proteção contra Xanthomonas vesicatoria (Cavalcanti et al., 2006).

Houve interação significativa $(\mathrm{P} \leq 0,05)$ entre solo suplementado ou não com NPK e indutores apenas em meloeiro Pele de Sapo em relação à altura da planta (Tabela 3), sendo observada redução nessa variável nas plantas tratadas com ASM nos dois tipos de solo e com BFC no solo com NPK. As plantas no solo natural, sem suplementação de NPK, apresentaram porte menor que aquelas no solo suplementado com NPK, nos tratamentos testemunha e ASM. Contudo, a maior redução na altura (23\%) foi nas plantas tratadas com ASM no solo com suplementação de NPK. Discordando dos resultados aqui obtidos, Dietrich et al. (2005), trabalhando com Arabidopsis sp. induzida por $\operatorname{ASM}\left(150 \mathrm{mg}\right.$ i.a. $\left.\mathrm{L}^{-1}\right)$, observaram redução no crescimento em função da diminuição da concentração de $\mathrm{N}$ e da água disponíveis. Em condições limitantes como a deficiência de nutrientes, em especial o N, o custo fisiológico da indução pode ter seus efeitos potencializados, uma vez que o $\mathrm{N}$ é um dos principais fatores limitantes do crescimento da planta, sendo fortemente afetado na expressão da resistência tanto constitutiva quanto induzida (Dietrich et al., 2004). No presente trabalho, o teor de NPK já existente no solo [N - 0,05 dag kg-1; P - $11\left(\mathrm{mg}\left(\mathrm{dm}^{3}\right)^{-1}\right) ; \mathrm{K}^{+}-0,06\left(\mathrm{cmol}_{\mathrm{c}}\right.$ $\left.\left(\mathrm{dm}^{3}\right)^{-1}\right)$ ] foi suficiente para o bom desenvolvimento da planta, não potencializando a fitotoxidez e/ou o custo fisiológico relacionado a indução de resistência, quando incrementado.

Entre os tratamentos com os indutores $\mathrm{e}$ as testemunhas houve diferença significativa $(\mathrm{P} \leq 0,05)$, independente do nível de NPK no substrato, para as variáveis AP, BFPA e BSPA (Tabela 3). As plantas de meloeiro Amarelo tratadas com ASM apresentaram redução na $\mathrm{AP}$ e BFPA de 24 e $41 \%$, respectivamente, e com BFC na BFPA de 17\%. Entretanto, em Pele de Sapo os dois indutores reduziram a BFPA e BSPA em 27 e $22 \%$ (BFC) e 34 e $24 \%$ (ASM). Buzi et al. (2004) verificaram que sementes de melão tratadas com ASM e ácido metil jasmônico tiveram a germinação afetada, assim como houve diminuição no crescimento das plântulas, sendo este efeito atribuído ao custo da transferência de processos metabólicos envolvidos no crescimento para a síntese de compostos relacionados à defesa da planta. Os indutores ASM e $\mathrm{BFC}$ também podem ter causado fitotoxidez, reduzindo o crescimento das plantas de meloeiro, como verificado em outros patossistemas. Segundo Barros (2007), a aplicação de ASM em sementes de caupi na concentração de $0,5 \mathrm{~g}$ $\mathrm{L}^{-1}$ reduziu significativamente a produção e, pelo menos na fase inicial da cultura, causou subdesenvolvimento da planta, sugerindo fitotoxidez do produto na concentração utilizada. A aplicação de ASM também causou redução de $36 \%$ da massa seca de ciclâmens cultivados em substrato não infestado com o patógeno Fusarium oxysporum f. sp.

TABELA 3 - Efeito de indutores de resistência no desenvolvimento de plantas de meloeiro tipo Amarelo (hibrido AF4945) e tipo Pele de Sapo (híbrido Nilo) com 45 dias, em casa de vegetação

\begin{tabular}{|c|c|c|c|c|c|c|c|}
\hline \multirow[t]{3}{*}{ Tratamento $^{1}$} & \multicolumn{3}{|c|}{$\begin{array}{l}\text { Altura da planta- } \\
\text { AP }(\mathrm{cm})\end{array}$} & \multicolumn{2}{|c|}{$\begin{array}{l}\text { Biomassa fresca parte } \\
\text { aérea - BFPA (g) }\end{array}$} & \multicolumn{2}{|c|}{$\begin{array}{c}\text { Biomassa seca parte } \\
\text { aérea - BSPA (g) }\end{array}$} \\
\hline & \multirow[t]{2}{*}{ Amarelo } & \multicolumn{2}{|c|}{ Pele de Sapo } & \multirow[t]{2}{*}{ Amarelo } & \multirow{2}{*}{$\begin{array}{c}\text { Pele de } \\
\text { Sa po }\end{array}$} & \multirow[t]{2}{*}{ Amarelo } & \multirow{2}{*}{$\begin{array}{c}\text { Pele de } \\
\text { Sapo }\end{array}$} \\
\hline & & $\mathbf{N P K}^{+2}$ & NPK $^{-}$ & & & & \\
\hline Testemunha & $144,7^{3} a^{5}$ & $177,4^{4} \mathrm{aA}$ & $135,2 \mathrm{aB}$ & $21,0 \mathrm{a}$ & $28,0 \mathrm{a}$ & $1,3 \mathrm{a}$ & $1,9 \mathrm{a}$ \\
\hline Bioflavonóides cítricos $3 \mathrm{~mL}$ p.c. $\mathrm{L}^{-1}$ & $131,1 \mathrm{a}$ & $148,8 \mathrm{bA}$ & $135,4 \mathrm{aA}$ & $17,3 \mathrm{~b}$ & $20,6 \mathrm{~b}$ & $1,1 \mathrm{a}$ & $1,4 \mathrm{~b}$ \\
\hline Acibenzolar-S-Metil $50 \mathrm{mg}$ i.a.L $\mathrm{L}^{-1}$ & $109,2 \mathrm{~b}$ & $136,6 \mathrm{bA}$ & $112,8 \mathrm{bB}$ & $12,3 \mathrm{~b}$ & $18,5 \mathrm{~b}$ & $0,8 \mathrm{a}$ & $1,4 \mathrm{~b}$ \\
\hline $\mathrm{CV} \%$ & 8,0 & 8,1 & & 15,2 & 26,1 & 9,9 & 26,8 \\
\hline \multicolumn{8}{|c|}{ 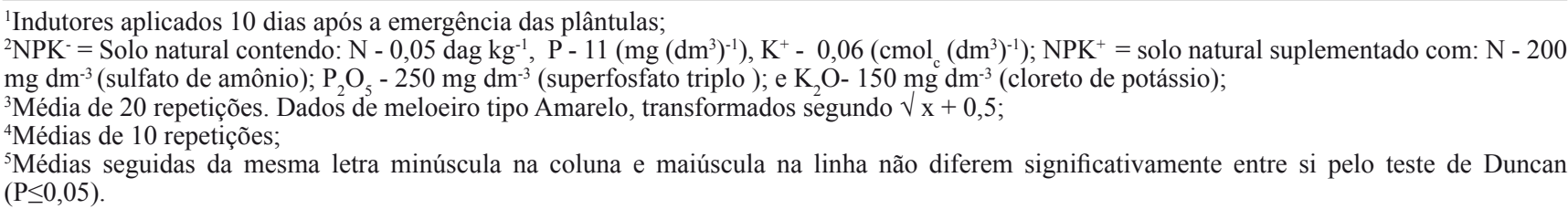 } \\
\hline
\end{tabular}


Efeito de acibenzolar-S-metil, mananoligossacarídeo e bioflavonóides cítricos...

cyclaminis (Elmer, 2006), em estudo para o controle da murcha desta ornamental.

Tanto o ASM quanto o BFC reduziram o desenvolvimento das plantas de meloeiro. Portanto, para que seja viável a utilização desses indutores num programa de manejo integrado da mancha-aquosa em meloeiro é necessário que a fitotoxicidade e/ou o custo da indução sejam compensados pela diminuição da intensidade da doença, uma vez que esses produtos foram eficientes no controle da mancha-aquosa (Tabela 2). Nesse sentido, Silva et al. (2002) observaram que a aplicação de ASM (1g $20 \mathrm{~L}^{-1}$ de água) em parcelas de meloeiro elevou em quase o dobro a produtividade em relação à testemunha, compensando portanto, os custos financeiros com a utilização do produto. Sales Júnior et al. (2007) testando o ASM $\left(25 \mathrm{~g} \mathrm{ha}^{-1}\right.$ e $50 \mathrm{~g}$ ha $^{-1}$ ) também obtiveram eficiência no controle da manchaaquosa e aumento da produtividade.

\section{AGRADECIMENTOS}

Os autores agradecem ao Conselho Nacional de Desenvolvimento Científico e Tecnológico - CNPq e Fundação de Amparo à Ciência e Tecnologia do Estado de Pernambuco - FACEPE pela concessão de auxílio financeiro (APQ 0350-5.01/06) e bolsas de Produtividade em Pesquisa.

\section{REFERÊNCIAS BIBLIOGRÁFICAS}

Araújo DV, Mariano RLR, Michereff SJ (2005) Métodos de inoculação de Acidovorax avenae subsp. citrulli em melão. Summa Phytopathologica 31:66-70.

Barros MC (2007) Efeito de Cowpea severe mosaic vírus na taxa fotossintética e na produtividade de caupi Vigna unguiculata L. (Walp) e avaliação da eficiência do acibenzolar-S-metil na indução de resistência ao mosaico severo. Dissertação de Mestrado. Universidade Federal de Alagoas. Rio Largo AL.

Buzi A, Chilosi G, de Sillo D, Magro P(2004) Induction of resistance in melon to Didymella bryoniae and Sclerotinia sclerotiorum by seed treatments with acibenzolar-Smethyl and methyl jasmonate but not with salicylic acid. Journal of Phytopathology 152:34-42.

Cavalcanti FR, Resende MLV, Zacaroni AB, Ribeiro Junior PM, Costa JCB, Souza RM (2006) Acibenzolar-S-metil e Ecolife ${ }^{\circledR}$ na indução de respostas de defesa do tomateiro contra a mancha bacteriana (Xanthomonas vesicatoria). Fitopatologia Brasileira 31:372-380.

Dietrich R, Ploss K, Heil M (2004) Constitutive and induced resistance to pathogens in Arabidopsis thaliana depends on nitrogen supply. Plant, Cell and Environment 27:896-906.

Dietrich R, Ploss K, Heil M (2005) Growth responses and fitness cost after induction of pathogen resistance depend on environmental condition. Plant, Cell and Environment 28:211-222.

Elmer WH (2006) Effects of acibenzolar-S-methyl on the suppression of fusarium wilt of cyclamen. Crop Protection 25:671676.

Guzzo SD (2004) Aspectos bioquímicos e moleculares da resistência sistêmica adquirida em cafeeiro contra Hemileia vastatrix. Tese de Doutorado. Piracicaba SP. ESALQ, Universidade de São Paulo.

Huang Y, Deverall BJ, Tang WH, Wang W, Wu FW (2000) Foliar application of acibenzolar-S-methyl and protection of postharvest Rock melons and Hami melons from disease. European Journal of Plant Pathology 106:651-656.

Lang JM, Gent DH, Schwartz HF (2007) Management of xanthomonas leaf blight of onion with bacteriophages and a plant activator. Plant Disease 91:871-878.

Mariano RLR, Silveira EB (2002) Mancha-aquosa: importante bacteriose de meloeiro no Brasil. In: Moura RM, Mariano RLR (Eds.) Anais da Academia Pernambucana de Ciência Agronômica. Recife. Academia Pernambucana de Ciência Agronômica. v.1, pp. 79-88.

McKinney RH (1923) Influence of soil temperature and moisture on infection of wheat seedlings by Helminthosporium sativum. Journal of Agricultural Research 26:195-218.

Mohan Babu R, Sajeena A, Samundeeswari AV, Sreedhar A, Vidhyasekeran P, Reddy MS (2005) Induction of bacterial blight (Xanthomonas oryzae pv. oryzae) resistance in rice by treatment with acibenzolar-S-methyl. Annals of Applied Biology 143:333340 .

Nascimento CWA, Amarasiriwardena D, Xing B (2006) Comparison of natural organic acids and synthetic chelates at enhancing phytoextraction of metals from a multi-metal contaminated soil. Environmental Pollution 140:114-123.

Nascimento MTA, Sales Júnior R, Nunes GHS, Amaro Filho J, Mascarenhas, RS, Pereira EWL (2003) Eficácia de Acibenzolar-Smethyl como indutor de resistência a fitopatógenos em meloeiro tipo pele de sapo. Fitopatologia Brasileira 28:339.

Sales Júnior R, Alves FML, Mendes MAS, Ferreira HA (2005) Utilização de indutores de resistência no controle do oídio em meloeiro. Caatinga 18:267-271.

Sales Júnior R, Pontes Filho FST, Nunes GHS, Torres GRC (2007) Eficiência de acibenzolar-S-metil e oxicloreto de cobre no controle de Acidovorax avenae subsp. citrulli, agente causal da mancha-aquosa no meloeiro. Revista de Biologia e Ciências da Terra 7:66-70.

Shaner G, Finney RE (1977) The effect of nitrogen fertilization on the expression of slow-mildewing resistance in knox wheat. Phytopathology 67:1051-1056.

Silva EC, Sales Júnior R, Maracajá PB, Silva GF, Costa FM, Marinho REM (2002) Utilização de indutor de resistência à mancha-aquosa em plantas de meloeiro. Caatinga 15:39-42.

Sticher L, Mauch-Mani B, Métraux JP (1997) Systemic acquired resistance. Annual Review of Phytopathology 35:235-270. 